\title{
Education for Science and Science for Education: more than a Play upon Words
}

\author{
Danielle Grynszpan/ ${ }^{+}$, Tania C Araújo-Jorge*
}

\author{
Laboratório de Educação Ambiental em Saúde, Departamento de Biologia *Laboratório de Biologia Celular, \\ Departamento de Ultrestrutura e Biologia Celular, Instituto Oswaldo Cruz, Av. Brasil 4365, 21045-900 \\ Rio de Janeiro, RJ, Brasil
}

\begin{abstract}
In the celebration of the Oswaldo Cruz Institute centenary, we wanted to stress our concern with the relationship between two of its missions: research and education. What are the educational bases required for science and technology activities on health sciences for the future years? How can scientists collaborate to promote the popularization of academic knowledge and to improve a basic education for citizenship in an ethic and humanistic view?

In this article we pointed out to need of commitment, even in the biomedical post-graduation level, of a more integrated philosophy that would be centered on health education, assuming health as a dynamic biological and social equilibrium and emphasizing the need of scientific popularization of science in a cooperative construction way, instead of direct transfer of knowledge, preserving also macro views of health problems in the development of very specific studies.

The contemporary explosion of knowledge, particularly biological knowledge, imposes a need of continuous education to face the growing illiteracy. In order to face this challenge, we think that the Oswaldo Cruz Institute honors his dialectic profile of tradition and transformation, always creating new perspectives to disseminate scientific culture in innovated forms.
\end{abstract}

Key words: scientific education - health education - science popularization

In the celebration of the centenary of the Oswaldo Cruz Institute (IOC), the theme "Educational Basis for Biomedical Research" was chosen to open the International Symposium in order to stress the institution's concern with the relationship between its two missions: research and education. This is an attempt to bring up for debate the integration of the two as an expression of the institutional project. In addition to its goal of qualifying health professionals by conveying scientific knowledge, the Institute also holds the responsibility of being a locus of criticism, capable of reproducing but also, and mainly, of questioning and producing new knowledge. This capacity has been the hallmark of IOC academic predicates during this century, which have made the Institute stand out in the field of biomedical research at the national and international levels.

In this round-table we asked outstanding colleagues to address those issues. All the invited

\footnotetext{
${ }^{+}$Corresponding author. Fax: +55-21-560.6474. E-mail: danielle@ioc.fiocruz.br Received 7 August 2000

Accepted 4 September 2000
}

speakers collaborated effectively for the development of science education and popularization, especially in the domain of life sciences. They all innovate in science, and were (and still are) important masters of many generations of scientists engaged on a humanistic position. These masters testify the integration between research and education, by acting at many levels and by contributing for the development of different scientific education project for teachers or for the production of educational products and materials. Their contributions will help us to analyze our own reality and pave ways that support the pioneer position of this institution, in its search to predict issues linked to health and science education.

As the title of our contribution depicts, the speakers in this round-table will approach two main questions: (1) what are the educational basis required for science and technology activities on health sciences for the future years? How can knowledge be taught and promoted?; and (2) what can science do to improve scientific education for citizenship? As "chairwomen" of this session, we want to address these questions briefly, by indicating how scientists in this Institute are dealing with them and what the perspectives are for an effective intervention on this area in the coming years. 


\section{BIOMEDICAL EDUCATION IN A CHANGING SOCIETY}

In our times scientific education, especially biomedical education, is facing the challenge of professional training for a changing society, thus it requires a growing social and ethic commitment and an interdisciplinary approach (Griner \& Danoff 2000). We need then to think of educational strategies that promote a permanent effort to stimulate scientific vocation, to expand creativity on science and to increase horizontal interaction between the distinct areas of biomedical knowledge. It is also important to emphasize the contribution given by scientists to society, which indicates their role as answers providers of questions linked to life quality. This must be associated with a more humanistic focus on biological and health sciences, and also with the transmission of a correct and up to date knowledge, using several instruments for science popularization and promoting a participant construction of knowledge about health all over the country.

Innovation in this field of training new generations of scientists may be expressed by an approach which assumes health as a dynamic equilibrium process and no longer as a state of well-being or as the absence of disease. Etiologically related to the biological and the social environments combined together, the multi-causal origin of diseases is another new perspective in which the post-graduation courses could develop, as Leselbaum (1998) highlights, a philosophy in common. This philosophy would be centered on health education instead of on a sanitary focus with a hygienistic view. A more democratic orientation, which integrates scientists and community members in a cooperative construction of knowledge has proven to be more fertile as a way to face the health problems of the Brazilian population. Direct transfer of scientific technology, as expert lectures or explanations, are not effective for learning, even at the post-graduation level, and favors a dependent attitude on the part of the communities.

Another educational challenge for biomedical research is the development of very specific studies, yet keeping and preserving macro views upon health problems at the same time. How to make more specific research without losing sight of the whole? Given the hard competition in the biomedical research field, an issue that arises for education from said challenge is the trend in students/ professionals to adopt personal purposes as a priority, without having any social commitment. The accessibility of ethical committees for biomedical research is then introduced into this discussion. In spite of the counseling nature of their intervention (Chevenement 1986), those committees are suc- cessfully attracting the attention of scientists, physicians and other people who wish to participate on a reflection about the evolution of science. This intensifies the importance of reliability on technological development, the meaning of research and the value of knowledge acquirement.

EDUCATIONAL BASIS REQUIRED FOR SCIENCE AND TECHNOLOGY ACTIVITIES ON HEALTH SCIENCES FOR THE FUTURE YEARS: TRADITION AND TRANSFORMATION

At the IOC we live in a permanent dialectic situation that assembles tradition and transformation. If, on the one hand, we feel the weight of being an ancient institution, on the other hand and concomitantly, we have incorporated a vow in fostering the continuous study of new biological conceptions, aiming at developing research and health services. All this goes hand in hand with the commitment of professional training to act at different levels. Oswaldo Cruz and Carlos Chagas memories are present in the post-graduation programs and in the technical courses. They are reflected on the high quality of the study programs and on the close association between basic research and fieldwork, with a clear intention of solving the health problems that affect the Brazilian population. However the multidisciplinary character and the ethic position should intersect in a socio-cultural context and provide a renewed concept of health. We should preserve what is called by Lakatos (apud Matalon 1998) as the "hard core", the essence, but we need to modify the educational programs or to propose new programs, which are suitable for the transformations of society, holding on to the responsibility entailed from the advances in field research of life sciences.

Basic and operative research on the health domain is the main mission of IOC and its centenary relevant contribution can be traced in other reports on this meeting. Engaged and intelligent people, whom in turn also train engaged and intelligent people, form successive generations of scientists and carry out research. Graduate courses are not enough to form scientists and post-graduated/PhD training is absolutely required. The quality and quantity input of those who have reached this level of education is then critical for the future of science all over the world. Moreover, a policy that will attract and support this staff in the system is the necessary counterpart, guaranteed by research grants and fellowships (Rodrigues \& De Meis 1996). However, both are currently undergoing a crisis: on one side of the scale, there is (1) a trend to reduce the number of curious and intelligent young people motivated to carry out scientific activity; and (2) there is also a reduction of the amount of university courses that train well qualified young 
candidates for post-graduate practice in research On the other side of the scale, the number of fellowships for master and $\mathrm{PhD}$ training are frozen or declining. Therefore, the quantity and the quality of the input for the scientist formation system, as well as the mechanisms to attract and support them economically, are both negative in this equation (De Meis 1998).

In recent meetings held to analyze the postgraduation discipline performance on the Institute, an important problem that became evident was the poor capacity of many candidates to solve problems, to read, to understand, to make out and to criticize the results of published papers, and a major deficiency in biological background knowledge. A great deal of time was dedicated to discussions about what the basic necessary knowledge is to train anyone as a $\mathrm{PhD}$ in Science, and no consensus has been achieved yet. Indeed, even what a $\mathrm{PhD}$ in Science is remains also as an important question, since most of best scientists are now ultraspecialists on specific matters. A physician or a biologist can be an extremely good scientist in a subject such as intracellular signaling, for example, and yet be unable to use trigonometry to solve problems, even those as old as the ones solved in ancient Egypt. This hypothetical specialist may know absolutely nothing about the chaos theory or about the non-Euclidean geometry. And the reciprocal is also true, a geologist may be the best specialist on Mars's volcanoes and yet not be able to understand what a gene or a transgene is. So the question of what should a scientist know to be a $\mathrm{PhD}$ in Science implies relative and complex answers, depending on which area he is going to act upon. The explosion of knowledge production in all areas, making it virtually impossible to follow all different areas of science, imposes a need for continuous education for all, from the youngest inexpert student to the oldest extremely expert scientist. Homemade and organized courses for continuous education are imperative for science institutions, not only for their professionals to be informed but also for the permanent renewing and refreshing of their way of thinking.

The subsequent questions of what should be taught to young scientists undergoing formation, and what should we ask them to learn before they join the science system are issues that need further clarification. The pragmatic operation however make it even more difficult to reflect upon those themes and we all do receive in our laboratories young chemists, biologists, physicians, etc. and we have to "review" with them the basic information in many fields, reaching even unexpected aspects of the theoretic courses, which are necessary to give them support on their scientific activity. An alter- native for this problem is to search actively for younger and younger people motivated for science and to merge them into laboratory activities as soon as possible, expecting the Darwinian mechanism of "natural selection" the take over. "Science Initiation" programs are the best formal expression of this policy. We went back to the ancient way of masters training their pupils. How and when should we interfere on this process: back at the elementary level; or at the college level; or during graduation; or only during post-graduation? These unanswered questions link this first part of our talk to the second one: What can we do?

\section{WHAT CAN SCIENCE DO TO IMPROVE SCIENTIFIC LITERACY AND EDUCATION FOR CITIZENSHIP?}

The problem of personal and student qualification for scientific activities that we have just introduced in the preceding paragraphs shows the top of the iceberg of the real problem: people are not literate to read nature directly by themselves, and they are not literate to receive and read disperse midia information on science either. They end up not being able to judge by themselves what is bad or good, what is right or wrong regarding science. When a soccer team wins or looses, people feel able to interpret the game and find out the reasons why those results were achieved (soccer is a good example in Brazil). However, when it comes to scientific matters, people feel completely incompetent to deem or judge. Is the genome project relevant? Is transgenic food good or bad? Should we stop research using animals? Those are questions that are open to social intervention at multiple levels and for which most people fell absolutely unprepared to answer. Common people are unable even to appreciate beauty on science work, differently from their capability to appreciate artwork, a piece of good music or the beauty of a poem. It is as if art were composed by culture (in its multiple aspects), but not by science. This problematic view of science outside of culture is spreading so rapidly on society that scientists (especially those from "hard" science) are frequently not included in the list of "intellectual" people, that commonly group artists working on literature, painting, sculpture, music, dance, theater, movies or, a big concession would be the case of social scientists such as anthropologists, for example. This illiteracy of the general public on scientific subjects (even - or specially - politicians and decision-makers) reflects a poor activity of science popularization, a mystification of scientific work and data, which influence young students against the ways that lead to a living science. In spite of all this, people are still fascinated with complex scientific problems such as how large is the universe, what is life and death, and so on. 
Given this context, what can scientists do? This is an absolute pertinent and timely question, since "What can science do for education?" will be the mote of a symposium organized by the Brazilian Academy of Science, coming up next June. In our opinion, scientists have three main fronts to work on to face the challenge of promoting scientific education for the general public, specially the younger ones.

First, to push forward the awareness of this problem within the scientific community itself, mainly among young post-graduating students that will make up the future generations of scientists. Discussions should frequently be held during the $\mathrm{PhD}$ training, thus engaging young scientists on concrete projects and actions to promote scientific education. In the last six years about 50 students in the Institute engaged on and developed 20 projects, of their own and exclusive choice, to popularize science.

A second front would be to develop real activities and movements of scientific education, geared to teachers, journalists, lawyers or to a more general public, conceived to popularize scientific information and to allow particular experiences on the scientific method, leading to personal discoveries or re-discoveries of views or concepts. A recent effort of the IOC in this direction has been the creation of a new post-graduation lato sensu course on "Science Education in Biology and Health". Based on the present gap between the accumulated academic knowledge, on the one hand, and the quantity and quality of what the public knows, and on the other hand, many of our researchers agreed to contribute for a new educational proposal. The first edition of this course will take place on the second semester of this year with the goal of putting scientists into direct contact with some of the main science mediators or those who are responsible for the deliberations that use biotechnological knowledge. By recognizing science influence in everyday life and the different partners involved in science popularization, this course extends the idea that scientific education must be understood as a fundamental premise for the exercise of citizenship, a sine qua non condition for re-insertion in culture.

A third front to engage scientists on is the active production of tools for science popularization. They should contribute to general publications for the public, magazines, books, text-books for school children and adolescents, exhibits for museums and galleries, informative web sites, videos, theater plays, and whatever other means could be thought of to disseminate information associated to emotion and discovery, the essence of science. At his centenary, the IOC is actively working on these three fronts. Here we will hear from our invited speakers why and how to move forward along this way.

\section{REFERENCES}

Chevenement JP 1986. Des principes pésolument universels. In M Azoulai \& P Jouannet, L'ÉthiqueCorps et Âme: Médecins et Biologistes à la Recherche d'une Nouvelle Morale, Autrement, Paris, p. 7274.

De Meis L 1998. Ciência e Educação: o Conflito Humano-tecnológico, Ed. do Autor, Rio de Janeiro, $198 \mathrm{pp}$.

Griner PF, Danoff D 2000. Sustaining change in medical education. J Am Med Assoc 18: 2429-2431.

Leselbaum N 1998. "Éducation sanitaire", "Promotion", "Prévention", "Éducation à la Santé". In Éducation à la Santé - Rôle et Formation des Personnels d'Éducation, Institut National de Recherche Pédagogique, Paris, p. 131-138.

Matalon B 1998. La marche des idées scientifiques: évolution ou révolutions? Sc Hum 21: 24-26.

Rodrigues PS, De Meis L 1996. Challenges for the science education in the western hemisphere: a Brazilian perspective. Annals of the Symposium: 20th Century Science Beyond the Metropolis, ORSTOM, Paris. 